\title{
Quality of Life in Keratoconus: Evaluation With Keratoconus Outcomes Specific Questionnaire (KORQ)
}

roberto damian pacheco pinto ( $\sim$ rpacheco42@gmail.com )

State University of Campinas

Ricardo Yuji Abe

State University of Campinas

Flavia Cid Gomes

State University of Campinas

Paulo Rodolfo Tagliari Barbisan

State University of Campinas

Alexandre Fattah Martini

State University of Campinas

Daniel de Almeida Borges

State University of Campinas

Arthur gustavo Fernandes

Universidade de São Paulo

Carlos Eduardo Leite Arieta

State University of Campinas

Monica Alves

State University of Campinas

\section{Research Article}

Keywords: Keratoconus Outcomes Research Questionnaire (KORQ), cross-sectional study, allergic conjunctivitis, keratoconus stage, best-corrected visual acuity (BCVA)

Posted Date: April 29th, 2021

DOl: https://doi.org/10.21203/rs.3.rs-465823/v1

License: (c) (1) This work is licensed under a Creative Commons Attribution 4.0 International License.

Read Full License 


\section{Abstract}

Purpose: To assess quality of life in keratoconus patients using the Keratoconus Outcomes Research Questionnaire (KORQ) translated and validated to Portuguese language. KORQ is the only validated keratoconus specific questionnaire and has high rating for psychometric properties.

Methods: In this cross-sectional study enrolled 100 patients with keratoconus from a tertiary referral eye hospital, from April 2018 to June 2019. Associations between age, gender, allergic conjunctivitis, keratoconus stage, best-corrected visual acuity (BCVA), maximum simulated keratometry (Kmax), steep keratometry (K2), pachymetry, treatments performed, hydrops and KORQ scores were evaluated with univariate (Wilcoxon test and the Kruskal Wallis test) and multivariate linear regression with stepwise backward modeling. Lower scores of KORQ are associated with better quality of life, as well as higher scores are associated with greater impairment of functional activities and symptoms.

Results: Out of the 100 patients, mild, moderate and severe keratoconus, was observed in $15 \%, 46 \%$ and $39 \%$ of participants, respectively. Univariate analysis showed lower values for function scores with male gender $(p<0.05)$ and both functional and symptoms scores statistically associated with $B C V A<0.3$ (LogMAR) $(p<0.05)$. Multivariate analysis indicated significantly lower functional scores in individuals with BCVA<0.3 $(p<0.001)$ and those with history of crosslinking treatment $(p=0.022)$, while symptom scores were only statistically associated with BCVA<0.3 $(p<0.001)$.

Conclusions: In patients with keratoconus, BCVA in the better eye and history of crosslinkig are factors were associated with better quality of life scores using KORQ.

\section{Introduction}

Keratoconus it is a progressive corneal disease with typical onset in adolescence or early adulthood, although cases of severe keratoconus have been reported in children as young as 4 years of age. ${ }^{1}$ It is a progressive asymmetric corneal disease characterized by steepening and distortion, apical thinning, and central scarring of the cornea. ${ }^{2}$ After onset, keratoconus can progress steepening and increasing irregularity of corneal parameters, as worsening vision. ${ }^{3}$ Treatment of keratoconus consists of spectacles, contact lenses, intrastromal corneal ring implants and corneal collagen crosslinking ${ }^{4}$, and when these treatment options are no longer effective for vision rehabilitation, lamellar or penetrating keratoplasty. ${ }^{5}$

Increasing attention has been given to the assessment of health-related quality-of-life (QoL) outcome measures in clinical trials during the past 3 decades. Vision-related quality-of-life (VQRL) is a person's satisfaction with visual function and how visual ability affects life. ${ }^{6}$ Keratoconus significantly impacts on VRQL with a substantial number of patients experiencing a decline in their VRQL over time. ${ }^{6,7}$ Even the simplest rehabilitation methods such as spectacles or contact lenses fit can affect QoL due to negative effects on cosmesis and/or inconvenience in handling. ${ }^{8-10}$ 
Questionnaires have been increasingly implemented as a tool to assess the QoL related to a specific disease, quantify symptoms, evaluate disease natural course and determine the impact of treatment strategies. Generic or ophthalmic patient-reported outcome (PRO) measures that are not specific to keratoconus may not include essential items that capture unique, keratoconus-specific QoL issues 3,11 , and studies that have investigated the QoL impact of keratoconus have used PRO instruments developed for other conditions, such as cataract or refractive error ${ }^{12}$, once there was no keratoconus-specific PRO instrument. An accurate measurement of QoL requires high-quality PRO measures. Recent study evaluating QoL in keratoconus using existing questionnaires concluded that this aspect of the disease would be better evaluated by using quality of life questionnaire specifically designed to keratoconus. ${ }^{13}$ However, only recently a psychometrically robust and valid instrument to assess the impact of keratoconus on activity limitation and symptoms was created, called Keratoconus Outcomes Research Questionnaire (KORQ). ${ }^{14}$

A recent study evaluated psychometric properties of the KORQ by using both classical test theory and Rasch analysis and concluded that KORQ is a psychometrically robust PRO measure to evaluate QoL parameters in individuals with keratoconus, it is appropriate for clinical use and research settings. ${ }^{15}$ In addition, another study comparing the quality of life questionnaires already used for keratoconus concluded that KORQ was the only validated keratoconus specific questionnaire and had the highest rating for psychometric properties among all the questionnaires. ${ }^{16}$ Thus, KORQ is the recommended "gold standard" method for development and validation of a patient-reported outcome measure. ${ }^{17}$

Important issues regarding to QoL and disease impact remain to be accessed: (1) there is no previous study evaluating QoL in keratoconus with the application of KORQ in a group of patients and (2) misuse of QoL questionnaires can lead to misleading results, adding confusion and causing the negative contribution to the understanding of the impact of keratoconus. Thus, the aim of the present study is to evaluate the QoL in keratoconus patients, using KORQ.

\section{Methods}

The KORQ comprises 2 scales tool, 18 items "Activity Limitation" scale (Table 1) and 11 items "Symptoms" scale (Table 2). Each item has a 4-point rating scale with an additional "not applicable" option. The patient's score is obtained through a ready-to-use Microsoft excel scoring (available at http://links.Iww.com/OPX/A287 and http://links.Iww.com/OPX/A288) spreadsheets for the two scales of the KORQ. These spreadsheets can be used to convert respondents' raw scores into person measures in logits without having to run Rasch analysis when the study sample is similar to the original study. Each spreadsheet consists of three sheets labeled as "rawdata," "raschscore," and "raw to Rasch conversion." Users are required to register respondents' responses to items in numerical label (i.e. 1 to 4 ) in the "rawdata" sheet, and the corresponding Rasch scores automatically appears in the "raw to rasch conversion". ${ }^{14}$ Person measure data were rescaled from the original logit scale, with values from 0 to 100 , to better understand its meaning. Lower scores are associated with better quality of life, as well as higher 
scores are associated with greater impairment of functional activities and symptoms. The inclusion criteria encompassed participants aged 18 years and older with a previous diagnosis of keratoconus or those who underwent penetrating keratoplasty for keratoconus. Participants with other ocular comorbidities, significant systemic disease, or inability to read Portuguese and understand the questionnaire were excluded. The KORQ was applied in its Portuguese version, after proper translation and validation process of the original questionnaire. ${ }^{18}$

Table 1

KORQ questionnaire Part I - Activity Limitation

\section{How much does your vision interfere with using a computer screen? \\ 10. How much do on coming lights interfere with your ability to see, to do your tasks?}

2. How much does your vision interfere with driving during the day?

3. How much does your vision interfere with driving during the night?

4. How much does your vision interfere with reading street signs?

5. How much does your vision interfere with watching TV?

6. How much does your vision interfere with walking up/down steps?

7. How much does your vision interfere with avoiding objects in your path?

8. How much does your vision interfere with your ability to do your job?

9. How much does your vision interfere with seeing in the distance?
11. How much does your vision interfere with doing fine tasks at near?

12. How much does your vision interfere with doing your hobby?

13. How much does your vision interfere with recognizing faces?

14. How much does your vision interfere with seeing in poor light?

15. How much does your vision interfere with doing household tasks? (e.g. cleaning, ironing, washing, washing up)

16. How much does your vision interfere with judging depth?

17. How much does your vision interfere with seeing small objects in the distance? (e.g. golf ball, darts)

18. How much does your vision interfere with sighting tasks? (e.g. camera, microscope, binoculars etc.)

KORQ: Keratoconus Oucomes Research Questionnaire 
Table 2

KORQ questionnaire Part II - Symptoms

\section{How much are you troubled by distorted vision?}

2. How much are you troubled by glare and wearing sunglasses all the time?

3. How much does a bright sunny day interfere with your ability to see, to do your tasks?

4. How much are you troubled by wearing rigid gas permeable contact lenses?

5. How much are you troubled by headaches when wearing your glasses/contact lenses?

\section{How much are you troubled by windy days?}

8. How much are you troubled when you are tired?

9. How much are you troubled by dry days?

10. How much are you troubled by dusty days?

11. How much are you troubled by smoky environments?

6. How much are you troubled by dry eyes?

KORQ: Keratoconus Oucomes Research Questionnaire

This study was conducted in the Department of Ophthalmology at the University of Campinas, after receiving approval from the Faculty of Heath Sciences Ethics Committee. The study was performed in accordance with the tenets of the Declaration of Helsinki. Consecutive keratoconus patients were enrolled from April 2018 to June 2019, referred from primary and secondary services. Upon enrollment into the registry, baseline parameters including demographic data, ocular history, and prior intervention(s) including previous cross-linking, best-corrected visual acuity (BCVA), steepest keratometry of the central 3 $\mathrm{mm}$ of the anterior corneal surface (K2), maximum simulated keratometry (Kmax), and pachymetry for each eye were recorded. Keratometry and pachymetry were measured using the Oculus Pentacam ${ }^{\circledR}$ (Oculus GmbH, Wetzlar, Germany).

Data analyzed included age, gender, history of allergy and use of eye drops, Best Corrected Visual Acuity (BCVA), keratometry, and pachymetry in the better and worse eye. BCVA was measured using a standardized protocol with Snellen acuity charts and results were converted to a LogMAR score. Keratoconus was classified by severity based on the Kmax in the better eye into the following: mild $(K \max <48 \mathrm{D})$, moderate $(\mathrm{Kmax} 48-55 \mathrm{D})$, and severe (Kmax > 55 D).

Data was analyzed using STATA 14.0 software (StataCorp LP, College Station, TX, USA). Frequency tables were used for descriptive analysis. Demographic and clinical variables were categorized according to a previous study that also investigated quality of life in patients with keratoconus ${ }^{13}$ (male or female, $\leq 27$ or $>27$ years old, $B C V A \leq 0.3$ or $>0.3$ (LogMAR), steep $K \leq 52.0$ diopters [D] or $>52.0$ [D], central corneal thickness $[C C T] \leq 450$ or $>450 \mu \mathrm{m}$, hydrops (at least one eye) or not, contact lens wear or not, history of corneal transplant or not, history of Intra corneal Ring Segment (ICRS) or not, history of Corneal Crosslinking (CXL) or not, surgical treatments or not). Uni and multivariate analysis were performed to investigate factors associated with functional and symptoms scores. Multiple Linear Regression model was determined according to stepwise backwards criteria. Correlations between continuous variables 
were assessed by Spearman test. For all tests, a significant $p$ value was considered when less than or equal to 0.05 .

We evaluated the psychometric properties of the KORQ using WINSTEPS (version 3.92.1). ${ }^{19}$ Person and item measures were examined in a Rasch model using infit and outfit item statistics. To test the hypothesis that the KORQ measures a single underlying construct, we initially evaluated the fit statistics, which were recorded as mean square standardized residuals (MNSQ); The fit of the Rasch model was evaluated with the infit and outfit statistics. Values between 0.5 and 1.5 are considered acceptable for MNSQ values of infit and outfit. ${ }^{20,21}$

\section{Results}

One hundred keratoconus patients with a median age of $27.47 \pm 7.02$ years (range 18-51 years) were included in this cross-sectional registry-based study. The mean value of $\mathrm{K}$ max was $53.65 \pm 5.00$ (D) in the best eye and $59.67 \pm 7.52$ (D) in the worst. The mean BCVA was $0.31 \pm 0.29$ and $0.68 \pm 0.40$ (LogMAR) in the better and worst eye, respectively; $67 \%$ of patients reported itching eyes, but only $31 \%$ reported use of medication; $26 \%$ wore rigid contact lens; $26 \%$ underwent crosslinking in at least 1 eye; $7 \%$ underwent intrastromal corneal ring and $8 \%$ underwent penetrating corneal transplantation. There were no statistically significant differences comparing male and female subgroups, in relation to the stage of keratoconus, hydrops or treatments performed. However, males in our study had slightly better visual acuity $(0.26 \pm 0.29$ versus $0.36 \pm 0.29, p=0.0451)$. Table 3 shows the study patients' demographic and clinical variables. 
Table 3

Demographic characteristics and clinical variables of keratoconus patients

\begin{tabular}{|c|c|}
\hline Parameter & Value \\
\hline Mean age (years-old), \pm SD & $27.47 \pm 7.02$ \\
\hline Sex (male/female) & $45 / 55$ \\
\hline Visual Acuity (LOGMAR), mean \pm SD & $0.31 \pm 0.29$ \\
\hline Better eye & $0.68 \pm 0.40$ \\
\hline \multicolumn{2}{|l|}{ Worse eye } \\
\hline Maximum keratometry (D), mean \pm SD & $53.64 \pm 5.00$ \\
\hline Better eye & $59.67 \pm 7.52$ \\
\hline \multicolumn{2}{|l|}{ Worse eye } \\
\hline Corneal curvature steep K (D), mean \pm SD & $49.44 \pm 4.23$ \\
\hline Better eye & $53.96 \pm 6.28$ \\
\hline \multicolumn{2}{|l|}{ Worse eye } \\
\hline Pachymetry (mean, microns) $\pm S D$ & $462.86 \pm 49.48$ \\
\hline Better eye & $433.27 \pm 69.13$ \\
\hline \multicolumn{2}{|l|}{ Worse eye } \\
\hline Stage $(1,2$ or 3 ; better eye), $n$ & $15(15.00)$ \\
\hline 1 & $46(46.00)$ \\
\hline 2 & $39(39.00)$ \\
\hline \multicolumn{2}{|l|}{3} \\
\hline Stage $(1,2$ or 3 ; worse eye), $n$ & $4(4.00)$ \\
\hline 1 & $26(26.00)$ \\
\hline 2 & $70(70.00)$ \\
\hline \multicolumn{2}{|l|}{3} \\
\hline Allergic conjunctivitis, $\mathrm{n}$ & $67(67.00)$ \\
\hline Use eye allergy medication, $\mathrm{n}$ & $31(31.00)$ \\
\hline Hydrops, n (\%) & $12(12.00)$ \\
\hline RGP contact lens wear, $n$ & $26(26.00)$ \\
\hline
\end{tabular}




\begin{tabular}{|ll|}
\hline Parameter & Value \\
\hline Crosslinking, $\mathrm{n}$ & $26(26.00)$ \\
\hline Intraestromal corneal ring, $\mathrm{n}$ & $7(7.00)$ \\
\hline Corneal transplant, $\mathrm{n}$ & $8(8.00)$ \\
\hline SD: Standard Deviation; D: Diopter; RGP: Rigid gas permeable \\
\hline
\end{tabular}

The psychometric properties of the KORQ were evaluated by WINSTEPS (version 3.92.1) in a Rasch model using infit and outfit item statistics. According to our analysis, we found that items Q10 from the "Activity Limitation" scale and items Q2, Q4, Q5 and Q9 from the Symptoms scale were misfitted (Table 4). After excluding items that were misfitted, we conducted a principal components analysis of the residuals (difference between the observed and expected responses) to investigate unidimensionality. Data were considered unidimensional if most of the variance is explained by the principal component and there is no significant explanation of the residual variance by the contrasts to the principal component. The raw variance explained by measures was $66.6 \%$ and $56.9 \%$ in the Activity Limitation and Symptoms scales, respectively. We found that the unexplained variance in 1 st contrast was 2.17 and 2.27 eigenvalues in the Activity Limitation and Symptoms scales, respectively. Despite that, we found that the disattenuated person-measure correlation in the first contrast was $>0.50$, suggesting that clusters belonged to random noise whether than multidimensionality issue. The person separation index is the ratio of the variance in the person measures for the sample to the average error in estimating these measures. It is a measure of how broadly the persons could be distinguished into statistically distinct levels. The person separation reliability coefficient describes the reliability of the scale to discriminate between the persons of different abilities. A person separation index of $\geq 2.0$ or a reliability value of $\geq 0.8$ represents the minimum acceptable level of separation. ${ }^{22}$ We found a person separation index of 3.84 and 2.46 in the Activity Limitation and Symptoms scales, respectively. We found a person reliability value of 0.94 and 0.86 for the Activity Limitation and Symptoms scales, respectively. This analysis provides information that the Portuguese translated version of the KORQ is unidimensional and a psychometrically valid tool to access QoL in patients with keratoconus. 
Table 4

Fit Statistics using Rasch Analysis with respective Subscales from Keratoconus Outcomes Research Questionnaire (KORQ).

\begin{tabular}{|c|c|c|c|c|}
\hline Questions & Subscale & Measure & Infit MNSQ & Outfit MNSQ \\
\hline Q1 & \multirow[t]{18}{*}{ Activity Limitation } & -0.27 & 0.93 & 1.01 \\
\hline Q2 & & 0.41 & 0.79 & 0.81 \\
\hline Q3 & & -1.36 & 0.98 & 0.88 \\
\hline Q4 & & -0.20 & 1.02 & 1.11 \\
\hline Q5 & & 0.30 & 0.75 & 0.83 \\
\hline Q6 & & 1.54 & 1.14 & 0.97 \\
\hline Q7 & & 1.48 & 0.99 & 1.02 \\
\hline Q8 & & 0.92 & 0.93 & 0.85 \\
\hline Q9 & & -2.31 & 0.86 & 0.80 \\
\hline Q10 & & -1.13 & 1.44 & 2.40 \\
\hline Q11 & & 1.66 & 0.95 & 0.86 \\
\hline Q12 & & 0.98 & 1.05 & 1.00 \\
\hline Q13 & & -0.78 & 1.38 & 1.39 \\
\hline Q14 & & -0.67 & 1.13 & 1.10 \\
\hline Q15 & & 1.84 & 1.04 & 0.89 \\
\hline Q16 & & -0.10 & 0.77 & 0.78 \\
\hline Q17 & & -2.01 & 0.97 & 0.83 \\
\hline Q18 & & -0.30 & 0.83 & 0.85 \\
\hline Q1 & \multirow[t]{7}{*}{ Symptoms } & -0.95 & 0.91 & 0.81 \\
\hline Q2 & & 0.78 & 1.35 & 1.27 \\
\hline Q3 & & 0.28 & 0.99 & 1.21 \\
\hline Q4 & & -0.73 & 1.91 & 2.42 \\
\hline Q5 & & 0.64 & 1.59 & 1.62 \\
\hline Q6 & & 0.28 & 0.98 & 0.96 \\
\hline Q7 & & 0.30 & 0.91 & 0.92 \\
\hline
\end{tabular}




\begin{tabular}{|c|c|c|c|c|}
\hline Questions & Subscale & Measure & Infit MNSQ & Outfit MNSQ \\
\hline Q8 & & 0.13 & 0.95 & 0.94 \\
\hline Q9 & & 0.27 & 0.49 & 0.49 \\
\hline Q10 & & -0.75 & 0.81 & 0.95 \\
\hline Q11 & & -0.26 & 0.62 & 0.62 \\
\hline
\end{tabular}

We used the final score obtained from the activity limitation and symptom questionnaire after excluding misfitted items, according to our Rasch analysis. Table 5 presents the KORQ score values according to clinical and demographic parameters. Univariate analysis shows no statistically significant differences in functional and symptom scores values according to age, steep keratometry, pachymetry, clinical and surgical treatments, stage and type of treatment $(p>0.05)$. It was observed a statistically significant association between gender and functional scores $(p=0.01)$, with men having lower scores than women, but without statistically significant differences in the symptom scores $(p=0.07)$. Moreover, a statistically significant association between visual acuity and functional $(p<0.001)$ and symptoms $(p<0.001)$ scores was also observed, with individuals with $B C V A<0.3$ LogMAR showing lower scores than individuals with $B C V A \geq 0.3$ LogMAR. 
Table 5

Univariate analysis on the association between clinical and demographic factors and Functional and Symptoms scores on the KORQ Questionnaire

\begin{tabular}{|c|c|c|c|c|}
\hline \multirow[t]{2}{*}{ Variable } & \multicolumn{2}{|l|}{ Functional score } & \multicolumn{2}{|c|}{ Symptoms score } \\
\hline & mean $\pm s d$ & $\begin{array}{l}p \\
\text { value }\end{array}$ & mean $\pm s d$ & $\begin{array}{l}p \\
\text { value }\end{array}$ \\
\hline Sex & $43.22 \pm 20.14$ & \multirow[t]{3}{*}{0.01} & $59.75 \pm$ & \multirow[t]{3}{*}{0.07} \\
\hline Female & \multirow[t]{2}{*}{$34.48 \pm 18.98$} & & & \\
\hline Male & & & $\begin{array}{l}02.18 \pm \\
19.01\end{array}$ & \\
\hline Age & $36.60 \pm 17.54$ & \multirow[t]{3}{*}{0.31} & $53.09 \pm$ & \multirow[t]{3}{*}{0.12} \\
\hline$\leq 27$ & \multirow[t]{2}{*}{$42.56 \pm 22.44$} & & & \\
\hline$>27$ & & & $20.69^{I}$ & \\
\hline Allergic conjunctivitis & $39.33 \pm 20.21$ & \multirow[t]{3}{*}{0.94} & $\begin{array}{l}57.54 \pm \\
18.79\end{array}$ & \multirow[t]{3}{*}{0.58} \\
\hline Yes & \multirow{2}{*}{$39.19 \pm 19.91$} & & & \\
\hline No & & & $\begin{array}{l}54.3 \pm \pm \\
21.41\end{array}$ & \\
\hline $\begin{array}{l}\text { Visual Acuity (better eye, in } \\
\text { LOGMAR) }\end{array}$ & \multirow[t]{3}{*}{$\begin{array}{l}48.63 \pm 19.1029 .56 \pm \\
16.01\end{array}$} & \multirow[t]{3}{*}{$<0.01$} & $\begin{array}{l}63.94 \pm \\
16.72\end{array}$ & \multirow[t]{3}{*}{$<0.01$} \\
\hline$\geq 0.3$ & & & \multirow{2}{*}{$\begin{array}{l}48.99 \pm \\
19.68\end{array}$} & \\
\hline$<0.3$ & & & & \\
\hline $\begin{array}{l}\text { Corneal curvature steep K (better } \\
\text { eye) }\end{array}$ & \multirow[t]{3}{*}{$\begin{array}{l}35.80 \pm 16.2441 .08 \pm \\
21.60\end{array}$} & \multirow[t]{3}{*}{0.24} & $\begin{array}{l}52.36 \pm \\
19.03\end{array}$ & \multirow[t]{3}{*}{0.16} \\
\hline$<52$ & & & \multirow{2}{*}{$\begin{array}{l}58.81 \pm \\
19.71\end{array}$} & \\
\hline$\geq 52$ & & & & \\
\hline Pachymetry (better eye) & $39.24 \pm 18.21$ & \multirow[t]{3}{*}{0.81} & $\begin{array}{l}56.45 \pm \\
1858\end{array}$ & \multirow[t]{3}{*}{0.74} \\
\hline$>450$ & \multirow[t]{2}{*}{$39.38 \pm 23.27$} & & & \\
\hline$\leq 450$ & & & $\begin{array}{l}56.91 \pm \\
21.72\end{array}$ & \\
\hline Stage better eye & $34.92 \pm 17.59$ & \multirow[t]{4}{*}{0.63} & $\begin{array}{l}53.15 \pm \\
17.64\end{array}$ & \multirow[t]{4}{*}{0.32} \\
\hline 1 & $40.43 \pm 18.77$ & & \multirow{2}{*}{$\begin{array}{l}54.45 \pm \\
18.94\end{array}$} & \\
\hline 2 & $39.62 \pm 22.42$ & & & \\
\hline 3 & & & $\begin{array}{l}60.51 \pm \\
20.83\end{array}$ & \\
\hline
\end{tabular}

CXL: corneal collagen cross-linking; RGP: rigid permeable gas; ICRS: intraestromal corneal rings; PKP: penetrating keratoplasty; K: keratometry; Data are mean \pm standard deviation, unless otherwise indicated 


\begin{tabular}{|c|c|c|c|c|}
\hline \multirow{4}{*}{$\begin{array}{l}\text { Variable } \\
\text { Treatment } \\
\text { No treatment / spectacles } \\
\text { RGP/ICRS/CXL/PKP }\end{array}$} & \multicolumn{2}{|l|}{ Functional score } & \multicolumn{2}{|c|}{ Symptoms score } \\
\hline & $40.73 \pm 19.58$ & \multirow[t]{3}{*}{0.36} & $55.56 \pm$ & \multirow[t]{3}{*}{0.91} \\
\hline & \multirow[t]{2}{*}{$37.96 \pm 20.50$} & & & \\
\hline & & & $20.83^{I}$ & \\
\hline Treatment & $40.37 \pm 20.05$ & \multirow[t]{3}{*}{0.44} & $56.18 \pm$ & \multirow[t]{3}{*}{0.88} \\
\hline No surgical treatments & \multirow{2}{*}{$37.44 \pm 20.08$} & & & \\
\hline Surgical treatments & & & $19.79^{ \pm}$ & \\
\hline RGP Contact Lens & $36.60 \pm 21.36$ & \multirow[t]{3}{*}{0.45} & $\begin{array}{l}57.40 \pm \\
2279\end{array}$ & \multirow[t]{3}{*}{0.79} \\
\hline Yes & \multirow{2}{*}{$40.23 \pm 19.58$} & & & \\
\hline No & & & $\begin{array}{l}56.34 \pm \\
18.55\end{array}$ & \\
\hline Crosslinking & $33.22 \pm 17.20$ & \multirow[t]{3}{*}{0.07} & $54.91 \pm$ & \multirow[t]{3}{*}{0.59} \\
\hline Yes & \multirow[t]{2}{*}{$41.42 \pm 20.59$} & & & \\
\hline No & & & 20.24 & \\
\hline Intraestromal Corneal Ring & $51.32 \pm 15.90$ & \multirow[t]{3}{*}{0.18} & $64.68 \pm$ & \multirow[t]{3}{*}{0.20} \\
\hline Yes & \multirow[t]{2}{*}{$38.38 \pm 19.32$} & & & \\
\hline No & & & $19.50^{ \pm}$ & \\
\hline Penetrating keratoplasty & $43.84 \pm 15.55$ & \multirow[t]{3}{*}{0.31} & $62.63 \pm$ & \multirow[t]{3}{*}{0.39} \\
\hline Yes & \multirow[t]{2}{*}{$38.89 \pm 20.37$} & & & \\
\hline No & & & $\begin{array}{l}56.09 \pm \\
19.58\end{array}$ & \\
\hline RGP Contact Lens & $39.23 \pm 22.17$ & \multirow[t]{5}{*}{0.39} & $\begin{array}{l}58.16 \pm \\
23.95\end{array}$ & \multirow[t]{5}{*}{0.71} \\
\hline ICRS & $49.00 \pm 32.10$ & & & \\
\hline CXL & $32.90 \pm 17.71$ & & $\begin{array}{l}62.42 \pm \\
25.31\end{array}$ & \\
\hline \multirow[t]{2}{*}{ Corneal Transplant } & \multirow[t]{2}{*}{$43.84 \pm 15.55$} & & $\begin{array}{l}54.54 \pm \\
18.73\end{array}$ & \\
\hline & & & $\begin{array}{l}62.63 \pm \\
20.43\end{array}$ & \\
\hline
\end{tabular}

CXL: corneal collagen cross-linking; RGP: rigid permeable gas; ICRS: intraestromal corneal rings; PKP: penetrating keratoplasty; K: keratometry; Data are mean \pm standard deviation, unless otherwise indicated 


\begin{tabular}{|c|c|c|c|c|}
\hline \multirow{2}{*}{$\begin{array}{l}\text { Variable } \\
\text { Hydrops }\end{array}$} & \multicolumn{2}{|c|}{ Functional score } & \multicolumn{2}{|c|}{ Symptoms score } \\
\hline & $40.15 \pm 17.50$ & \multirow[t]{3}{*}{0.71} & $61.15 \pm$ & \multirow[t]{3}{*}{0.36} \\
\hline Yes & \multirow[t]{2}{*}{$39.17 \pm 20.42$} & & \multirow{2}{*}{$\begin{array}{l}56.00 \pm \\
19.80\end{array}$} & \\
\hline No & & & & \\
\hline General & \multicolumn{2}{|l|}{$39.29 \pm 20.01$} & \multicolumn{2}{|l|}{$\begin{array}{l}56.62 \pm \\
19.63\end{array}$} \\
\hline \multicolumn{5}{|c|}{$\begin{array}{l}\text { CXL: corneal collagen cross-linking; RGP: rigid permeable gas; ICRS: intraestromal corneal rings; PKP } \\
\text { penetrating keratoplasty; K: keratometry; Data are mean } \pm \text { standard deviation, unless otherwise } \\
\text { indicated }\end{array}$} \\
\hline
\end{tabular}

Table 6 shows the result of multiple linear regression for functional and symptoms scores. A statistically significant association between functional score, visual acuity and history of crosslinking was observed. Individuals with BCVA $<0.3$ LogMAR have an average score of 18.39 lower than those with BCVA $\geq 0.3$ LogMAR and individuals with a history of crosslinking have an average score of 9.12 lower than those without a history. Regarding symptoms score, only visual acuity was associated with the final score with individuals with BCVA $<0.3$ LogMAR showing an average score 14.29 lower than those with BCVA $\geq 0.3$ LogMAR. The results are represented by boxplot in Fig. 1 .

Table 6

Multiple Linear Regression to Functional and Symptoms Scores according to stepwise backwards modeling

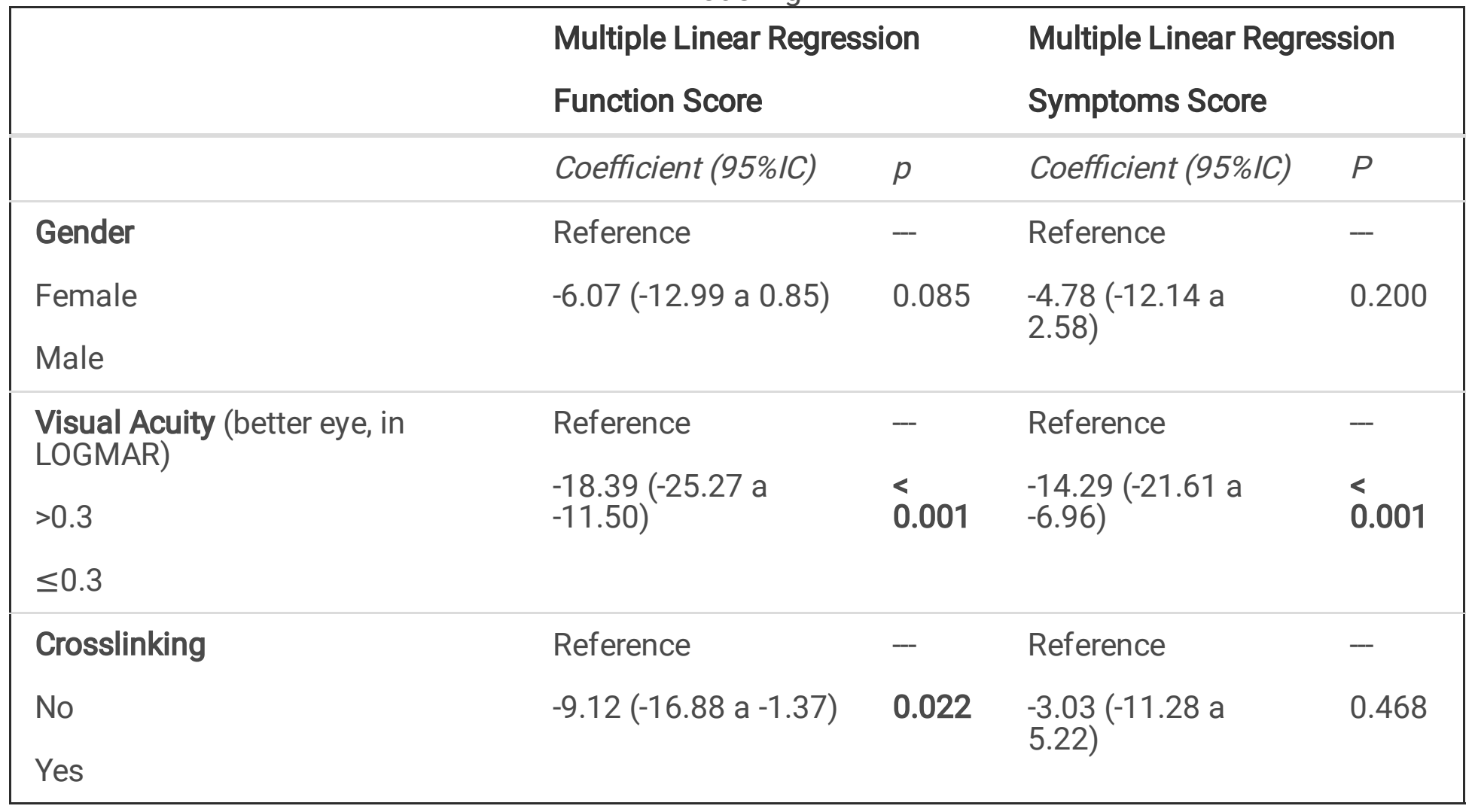


Spearman correlation test showed a positive correlation between visual acuity in LogMAR and both functional $(r=0.4934, p<0.0001)$ and symptoms $(r=0.4457, p<0.0001)$ scores. Figure 2 illustrates these results.

\section{Discussion}

Most of the existing questionnaires are first generation questionnaires based on classical test theory, which uses summary scoring. This type of scoring is an over simplistic method once assumes that all items in a scale or a questionnaire have an equal weight, and the response options are located at equal distance from each other. It falsely assumes categorical ordinal data as interval-level data ${ }^{17}$. Modern psychometric methods such as Rasch analysis, on the other hand, can convert categorical data into interval-level data using logarithmic transformation. ${ }^{23}$ Rasch analysis can use Andrich rating-scale and Partial-credit models to obtain the estimates of the required ability of each item, perceived ability of each subject, and the thresholds for each response category. ${ }^{23}$ In this study we evaluated the psychometric properties of KORQ using an Andrich rating scale model, corroborating previous studies showing that KORQ is a psychometrically robust PRO measure to evaluate QoL parameters in individuals with keratoconus. ${ }^{15,16}$ In this study, a validated version of the KORQ was applied in a large sample of keratoconus patients. The data presented herein represents the first cohort of patients evaluated by the KORQ tool.

In this sample, there was less impact in activity limitation and symptoms in those patients with better vision (visual acuity $<0.3$ LogMAR). We used the BCVA of the best-seeing eye based on previous studies that observed that ability to perform vision-related activities of daily living seems to be primarily a function of the vision in the best eye. ${ }^{24-26}$ The decline in QoL with worse visual acuity parallels findings of the Collaborative Longitudinal Evaluation of Keratoconus study, which similarly demonstrated that VA worse than 20/40 (decimal $=0.5$ ) and corneal curvature $\geq 52$ D were associated with significantly lower scores on all scales of the NEI-VFQ (National Eye Institute Visual Function Questionnaire). ${ }^{27}$ In accordance with our findings, Gothwal et a/ reported no statistically significant difference in the visionspecific functioning or emotional well-being between moderate and severe keratoconus groups and concluded that QoL did not vary as a function of disease severity in their cohort. ${ }^{28}$

In our study, multivariate analysis demonstrated that history of corneal crosslinking was statistically associated with functional scores. Corneal crosslinking was the only intervention among those evaluated that showed association in the functional score. Indeed, Cingu et al demonstrated that corneal collagen cross-linking led to significant improvements in keratometric readings including Kmax, associated with improved VRQoL and lower trait anxiety. ${ }^{29}$ Also, Labiris et al., ${ }^{30}$ while investigating the effects of CXL treatment on QoL of KC patients, found that dependency and mental health scores were reported to be better after CXL. They concluded that CXL treatment had halted the deterioration of QoL in these patients given the evidence showing gradual worsening of QoL in untreated KC patients. This reinforces the 
importance of this procedure, with benefits already known as limits the progression of keratoconus, not only reducing the need for transplantation ${ }^{31}$, but also in improving the quality of life.

Some limitations of our study might be pointed. First, patients with keratoconus were recruited from a single tertiary eye hospital; so, just few patients had early stages of the disease. Therefore, this cohort may not be representative of the Brazilian population. Second, this is a cross-sectional study of QoL in keratoconus patients. We could only report associations between clinical parameters and QoL scores but cannot establish any causative relationships in the absence of longitudinal evaluation. Besides that, despite the KORQ had excellent psychometric properties and is currently the recommended questionnaire to measure keratoconus outcomes, it only measures 2 domains of QoL: activity limitation and symptoms. Items on other QoL domains including psychosocial well-being and inconveniences are not yet included in the KORQ.

There are several potential implications of our study. This is the first study that applied KORQ to a group of keratoconus patients. We have shown that better visual acuity is the main variable associated with quality of life scores, which is in agreement with findings from other large case series, using distinct tools. $3,24,27$ With this in mind, improving visual acuity should be a constant goal in the treatment of keratoconus, through any currently available option, according to disease stage and improvement rate. Corneal CXL is a well-known procedure to stabilize keratoconus progression and we observed that CXL may have a significant impact on patient's quality of life. We also found few patients under medication for allergic conjunctivitis (31\%), despite of higher number of related symptoms report (67\%). Considering that continuous corneal micro trauma is an important and well-known risk factor for disease progression, it is mandatory that all patients receive education about allergy signs and symptoms to prompt recognize and treat acute episodes and to incorporate preventive measurements in daily life.

Our findings show that BCVA in the better eye and history of crosslinkig were factors associated with higher quality of life scores using KORQ. Strategies to prevent keratoconus from reaching severe stages, and consequently worse visual acuity, must be warranted to maintain QoL. Rehabilitation strategies are needed to improve QoL in those already managing severe disease and should focus on reading and mobility issues.

\section{Declarations}

\section{Data availability}

The data that support the findings of this study are available from the corresponding author, RDPP, upon request.

\section{Authors contributions:}

Roberto Damian Pacheco Pinto: Conceived and designed the analysis, collected the data, performed the analysis, wrote the paper 
Ricardo Yuji Abe: performed the analysis, wrote the paper

Flávia Cid Gomes: Conceived and designed the analysis, collected the data

Paulo Rodolfo Tagliari Barbisan: wrote the paper

Alexandre Fattah Martini: collected the data

Daniel de Almeida Borges: performed the analysis

Arthur Gustavo Fernandes: performed the analysis, wrote the paper

Carlos Eduardo Leite Arieta: Conceived and designed the analysis

Monica de Cassia Alves de Paula: Conceived and designed the analysis, performed the analysis, wrote the paper

\section{Conflict of Interest}

No conflicting relationships exist for any authors.

\section{Financial Support}

São Paulo Research Association (FAPESP) grant no. 2014/19138-5

\section{References}

1. Sabti, S., Tappeiner, C. \& Frueh, B. E. Corneal Cross-Linking in a 4-Year-Old Child With Keratoconus and Down Syndrome. Cornea. 34, 1157-1160 (2015).

2. Krachmer, J. H., Feder, R. S. \& Belin, M. W. Keratoconus and related noninflammatory corneal thinning disorders. Surv Ophthalmol. 28, 293-322 (1984).

3. Tan, J. C. K. et al. Vision-Related Quality of Life in Keratoconus: A Save Sight Keratoconus Registry Study. Cornea. 38, 600-604 (2019).

4. Siganos, C. S. et al. Management of keratoconus with Intacs. Am J Ophthalmol. 135, 64-70 (2003).

5. Frost, N. A., Wu, J., Lai, T. F. \& Coster, D. J. A review of randomized controlled trials of penetrating keratoplasty techniques. Ophthalmology. 113, 942-949 (2006).

6. Asaoka, R. et al. Patients have two eyes!: binocular versus better eye visual field indices. Invest Ophthalmol Vis Sci. 52, 7007-7011 (2011).

7. Kymes, S. M. et al. Changes in the quality-of-life of people with keratoconus. Am J Ophthalmol. 145, 611-617 (2008).

8. Downie, L. E. \& Lindsay, R. G. Contact lens management of keratoconus. Clin Exp Optom. 98, 299311 (2015). 
9. Kandel, H., Khadka, J., Goggin, M. \& Pesudovs, K. Impact of refractive error on quality of life: a qualitative study. Clin Experiment Ophthalmol. 45, 677-688 (2017).

10. Kandel, H. et al. Uncorrected and corrected refractive error experiences of Nepalese adults: a qualitative study. Ophthalmic Epidemiol. 25, 147-161 (2018).

11. Ahern, S., Ruseckaite, R. \& Ackerman, I. N. Collecting patient-reported outcome measures. Intern Med J. 47, 1454-1457 (2017).

12. Ortiz-Toquero, S. et al. The influence of the refractive correction on the vision-related quality of life in keratoconus patients. Qual Life Res. 25, 1043-1051 (2016).

13. Saunier, V. et al. Vision-related quality of life and dependency in French keratoconus patients: Impact study. J Cataract Refract Surg. 43, 1582-1590 (2017).

14. Khadka, J., Schoneveld, P. G. \& Pesudovs, K. Development of a Keratoconus-Specific Questionnaire Using Rasch Analysis. Optom Vis Sci. 94, 395-403 (2017).

15. Kandel, H. et al. Psychometric Properties of the Keratoconus Outcomes Research Questionnaire: A Save Sight Keratoconus Registry Study. Cornea 2019.

16. Kandel, H., Pesudovs, K. \& Watson, S. L. Measurement of Quality of Life in Keratoconus. Cornea 2019.

17. McAlinden, C. et al. Psychometric properties of the NEI-RQL-42 questionnaire in keratoconus. Invest Ophthalmol Vis Sci. 53, 7370-7374 (2012).

18. Pinto, R., Gomes, F., Alves, M. \& Arieta, C. Translation and validation of the Keratoconus Outcomes Research Questionnaire (KORQ) to portuguese.Arq Bras Oftalmol2020;Epub ahead of print.

19. Bond, T. G. \& Fox, C. M. Applying the Rasch model: fundamental measurement in the human sciences 2nd edn (Lawrence Erlbaum Associates Publishers, Mahwah, N.J, 2007).

20. Wright, B. L., Gustafson, J. \& Martin-Lof, P. Reasonable mean-square fit values. In: Vol 8. 3.; 1994:370.

21. Linacre, J. What do infit and outfit, mean-square and standardized mean? Rasch Measurement TransactionsRasch. Measurement Transactions. 16, 878 (2012).

22. Prieto, L., Alonso, J. \& Lamarca, R. Classical Test Theory versus Rasch analysis for quality of life questionnaire reduction. Health Qual Life Outcomes. 1, 27 (2003).

23. Lamoureux, E. L. et al. The Impact of Vision Impairment Questionnaire: an evaluation of its measurement properties using Rasch analysis. Invest Ophthalmol Vis Sci. 47, 4732-4741 (2006).

24. Sahebjada, S. et al. Impact of keratoconus in the better eye and the worse eye on vision-related quality of life. Invest Ophthalmol Vis Sci. 55, 412-416 (2014).

25. Steinberg, E. P. et al. The VF-14. An index of functional impairment in patients with cataract. Arch Ophthalmol. 112, 630-638 (1994).

26. Musch, D. C. et al. Assessment of health-related quality of life after corneal transplantation. Am J Ophthalmol. 124, 1-8 (1997).

27. Kymes, S. M. et al. Quality of life in keratoconus. Am J Ophthalmol. 138, 527-535 (2004). 
28. Gothwal, V. K. et al. Assessment of the impact of keratoconus on vision-related quality of life. Invest Ophthalmol Vis Sci. 54, 2902-2910 (2013).

29. Cingu, A. K. et al. Impact of Collagen Cross-linking on Psychological Distress and Vision and HealthRelated Quality of Life in Patients With Keratoconus. Eye Contact Lens. 41, 349-353 (2015).

30. Labiris, G. et al. Impact of keratoconus, cross-linking and cross-linking combined with photorefractive keratectomy on self-reported quality of life. Cornea. 31, 734-739 (2012).

31. Beckman, K. A. et al. Corneal crosslinking: Current protocols and clinical approach. J Cataract Refract Surg. 45, 1670-1679 (2019).

\section{Figures}

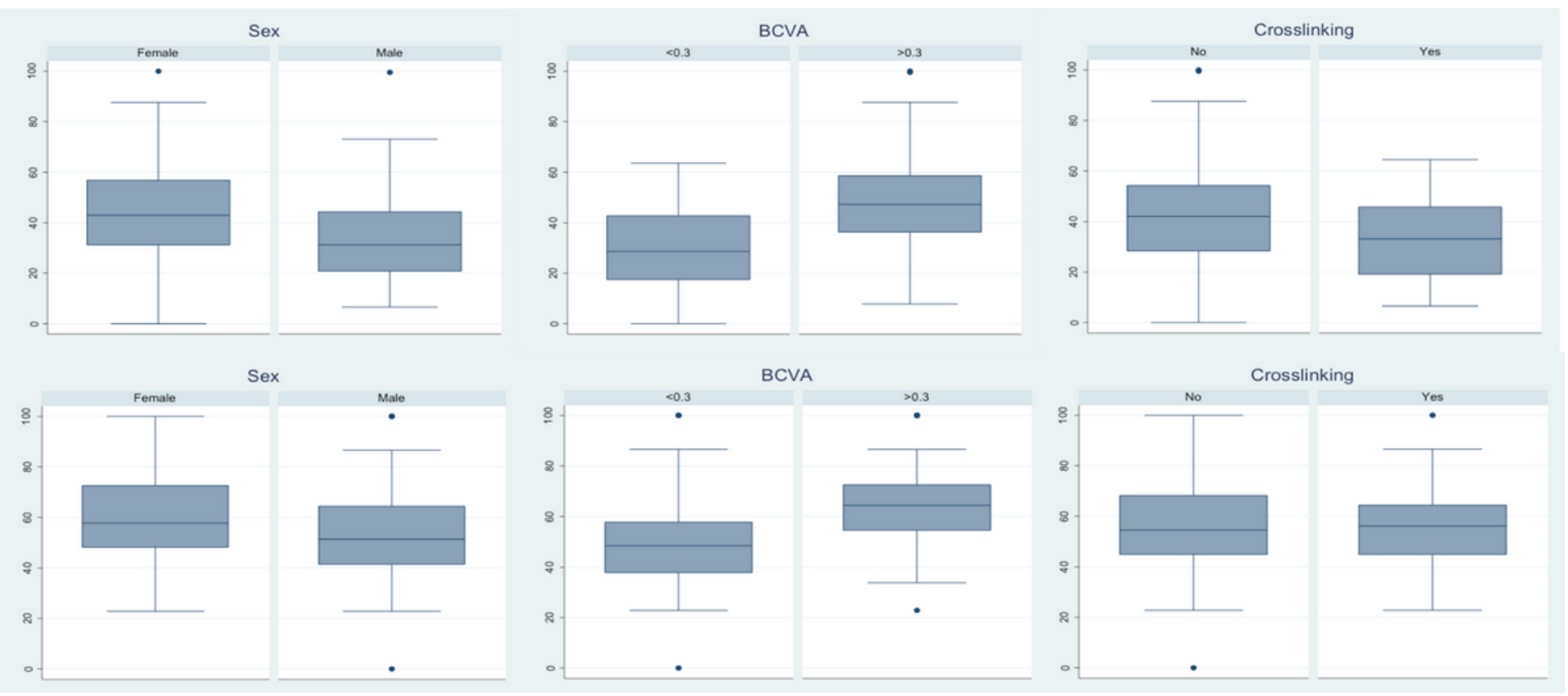

\section{Figure 1}

Above, Boxplots Functional Score according to Sex $(p>0.05), B C V A(p<0.001)$ and Crosslinking $(p=0.02)$. Below, Boxplots Symptom Score according to Sex $(p>0.05), B C V A(p<0.001)$ and Crosslinking $(p>0.05)$. 


\section{Funcional Score}

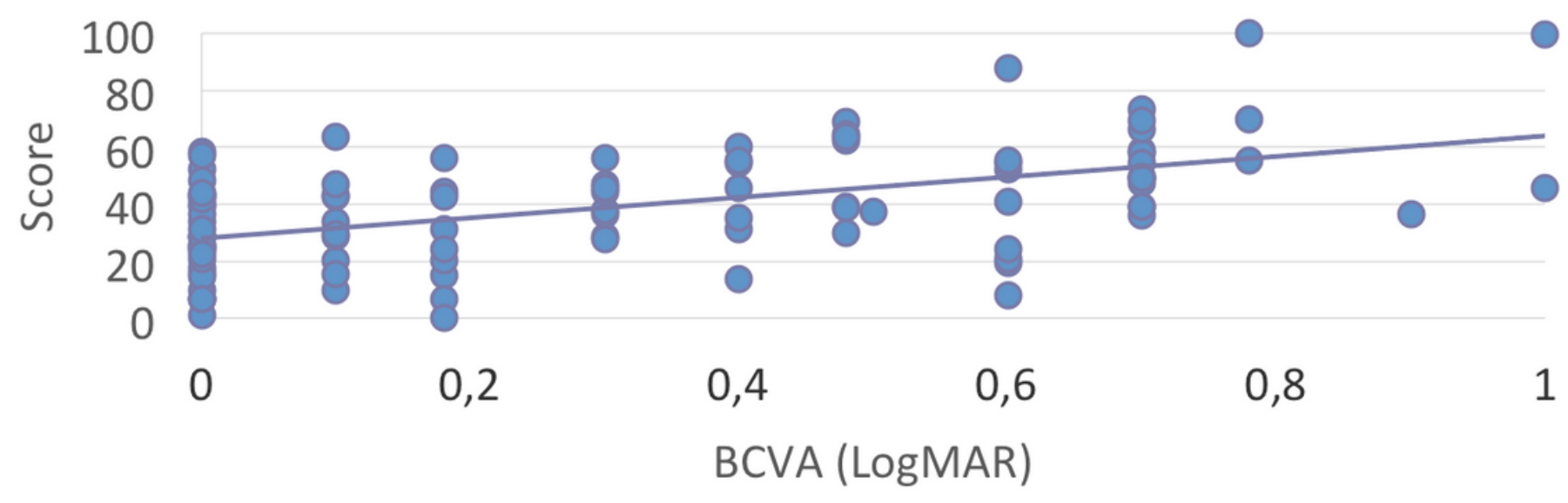

Symptoms Score

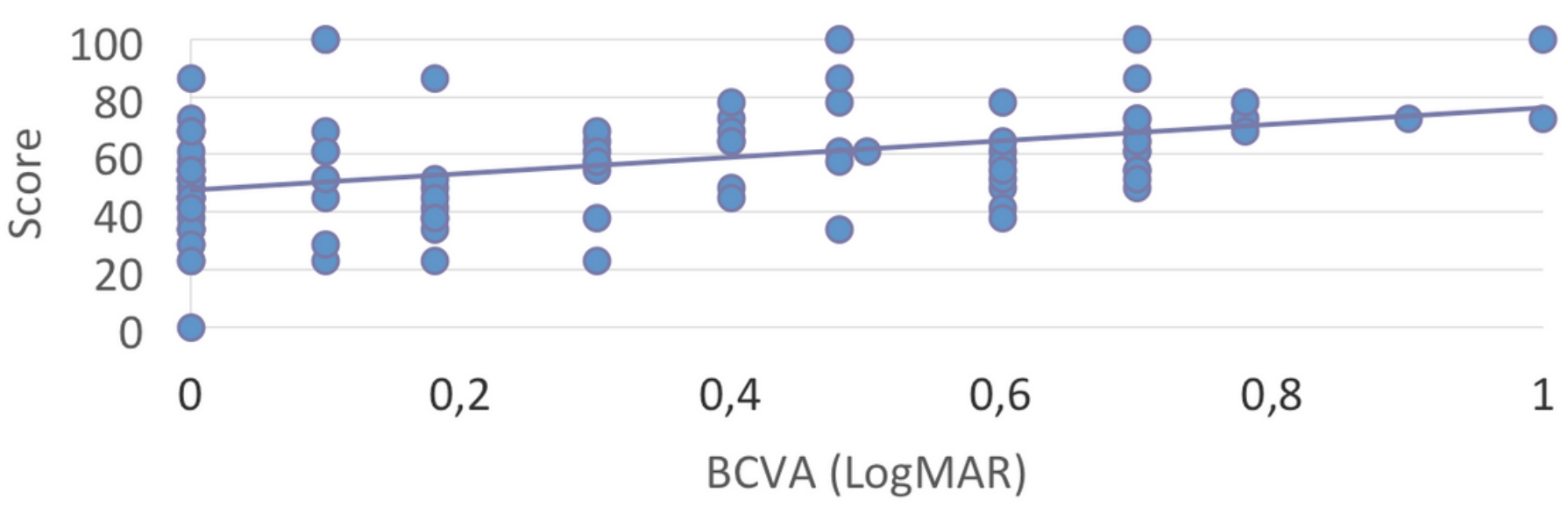

Figure 2

Spearman correlation test showed a positive correlation between visual acuity in LogMAR and both functional $(r=0.4934, p<0.001)$ and symptoms $(r=0.4457, p<0.0001)$ scores. 